Published in final edited form as:

J Am Acad Child Adolesc Psychiatry. 2013 December ; 52(12): 1294-1303.e1. doi:10.1016/j.jaac.

2013.09.008.

\title{
Preschool Anxiety Disorders in Pediatric Primary Care: Prevalence and Comorbidity
}

\author{
Dr. Lauren Franz, M.B.Ch.B., M.P.H., Dr. Adrian Angold, M.R.C.Psych., Dr. William \\ Copeland, Ph.D., Dr. E. Jane Costello, Ph.D., Dr. Nissa Towe-Goodman, Ph.D., and Dr. \\ Helen Egger, M.D. \\ Drs. Franz, Angold, Copeland, Costello, and Egger are with the Center for Developmental \\ Epidemiology, Duke University Medical Center. Dr. Towe-Goodman is with the Center for \\ Developmental Science, University of North Carolina-Chapel Hill
}

Abstract

Objective-We sought to establish prevalence rates and detail patterns of comorbidity for generalized anxiety disorder, separation anxiety disorder, and social phobia, in preschool aged children.

Method-The Duke Preschool Anxiety Study, a screen-stratified, cross-sectional study, drew from pediatric primary-care and oversampled for children at risk for anxiety. 917 parents of preschoolers (aged 2 to 5 years) completed the Preschool Age Psychiatric Assessment.

Results-Generalized anxiety disorder, separation anxiety disorder, and social phobia are common in preschool-aged children attending pediatric primary care. Three quarters of preschoolers with an anxiety disorder only had a single anxiety disorder. Generalized anxiety disorder displayed the greatest degree of comorbidity: with separation anxiety disorder (odds ratio $[\mathrm{OR}]=4.1,95 \% \mathrm{CI}, 2.0-8.5)$, social phobia $(\mathrm{OR}=6.4,95 \% \mathrm{CI}, 3.1-13.4)$, disruptive behavior disorders $(\mathrm{OR}=5.1,95 \% \mathrm{CI}, 1.6-15.8)$, and depression $(\mathrm{OR}=3.7,95 \% \mathrm{CI}, 1.1-12.4)$.

Conclusions-The weakness of association between generalized anxiety disorder and depression stands in contrast to substantial associations between these 2 disorders reported in older individuals. Attenuated associations in preschool aged children could translate into clinical

(C) 2013 American Academy of Child \& Adolescent Psychiatry. Published by Elsevier Inc. All rights reserved

Correspondence to Lauren Franz Center for Developmental Epidemiology, Duke University Medical Center, Department of Psychiatry and Behavioral Sciences, Box 3454, Durham NC 27710; lauren.franz@dm.duke.edu.

Supplemental material cited in this article is available online.

Disclosure: Dr. Franz has received research support from the Fogarty International Center at NIH. Dr. Angold has received research support from NIMH and the National Institute on Drug Abuse. Dr. Copeland has received research support from NIMH and the National Alliance for Research on Schizophrenia and Depression (NARSAD). Dr. Costello has received research support from the National Institute of Mental Health and the National Institute on Drug Abuse. Dr. Towe-Goodman has received research support from the National Institute of Child Health and Development. Dr. Egger has received research support from NIMH, the National Institute on Drug Abuse, the Duke Endowment, the Human Development Research Foundation, Autism Speaks, NARSAD, the Center for Disease Control and Prevention, and the Children's Brain Research Foundation. Drs. Costello and Angold are corecipients of the 2009 National Alliance for Research on Schizophrenia and Depression Ruane Prize for Outstanding Child and Adolescent Psychiatric Research. Drs. Costello and Angold coauthored the following assessment tools: Child and Adolescent Psychiatric Assessment (CAPA), Young Adult Psychiatric Assessment (YAPA), Child and Adolescent Impact Assessment (CAIA), Child and Adolescent Services Assessment (CASA), and Mood and Feelings Questionnaire (MFQ). Drs. Egger and Angold coauthored the following assessment tool: Preschool Age Psychiatric Assessment (PAPA). Dr. Egger co-authored the following assessment tool: the Manual for Disruptive Behavior Diagnostic Observational Schedule. No personal income has been derived from any of these measures.

Publisher's Disclaimer: This is a PDF file of an unedited manuscript that has been accepted for publication. As a service to our customers we are providing this early version of the manuscript. The manuscript will undergo copyediting, typesetting, and review of the resulting proof before it is published in its final citable form. Please note that during the production process errors may be discovered which could affect the content, and all legal disclaimers that apply to the journal pertain. 
opportunities for targeted early interventions, aimed at modifying the developmental trajectory of anxiety disorders.

\section{Keywords}

comorbidity; pediatric primary care; preschool anxiety disorders; prevalence

The public health burden of psychiatric disorders in preschool children is a problem whose scope is not well understood ${ }^{1-4}$. Over the last decade, studies of prescribing patterns in insurance databases have demonstrated dramatic increases in the prescription of psychotropic medications for preschool children ${ }^{5,6}$. This increase in psychopharmacologic treatment of young children has drawn attention to the neglected topic of diagnosis in the preschool years. Until recently, necessary epidemiological research on preschool mental health disorders was inhibited by the lack of reliable and valid assessment instruments. However, major advances have been made in the past decade with the development and psychometric testing of assessment instruments that map current nosologies such as DSM-IV and ICD-10 onto the symptoms and impairment of preschool children, as reported by parents and teachers. Psychometric testing has shown that such instruments are as reliable as those designed for older children, adolescents, and adults ${ }^{7}$.

In this paper we concentrate on preschool anxiety disorders. Many anxiety disorders have their onset in early childhood ${ }^{8}$. The limited research among preschool-aged children supports the notion that early childhood anxiety symptoms may cluster into diagnosticspecific groupings, similar to those found among older children ${ }^{9}, 10$. Generalized anxiety disorder, separation anxiety disorder, and social phobia, are thought to be among the most common, earliest onset, childhood psychiatric disorders, carrying substantial risk for anxiety disorders and depression in adulthood ${ }^{11-15}$, and for continuing comorbidity and impaired quality of life throughout the lifespan ${ }^{16-19}$. To date, few studies of preschool aged children, from reasonably representative samples, using structured psychiatric assessments with known psychometric properties, have reported on one or more anxiety diagnosis ${ }^{7,20-22}$. The range of prevalence estimates for generalized anxiety disorder reported in these studies is $0.6 \%$ to $6.5 \%$, while prevalence estimates of separation anxiety disorder range from $0.3 \%$ to $5.4 \%$, and social phobia range from $0.5 \%$ to $4.4 \%$. Anxiety disorders are thought to be highly comorbid at all ages ${ }^{23}$. Comorbidity data from the preschool period remains limited with studies tending to report co-occurrence between broad categories of emotional and behavioral disorders ${ }^{24,25}$. Comorbidity, even in the preschool years, is perhaps expected, as population-based twin studies indicate that the genetic liability for specific anxiety disorders partly overlaps ${ }^{26,27}$. Egger et al. ${ }^{7}$ reported that $8 \%$ of preschoolers met criteria for more than one psychiatric disorder. Of those who met criteria for a disorder, $51.6 \%$ had a single type of disorder, $25.8 \%$ had 2 , and $22.6 \%$ had 3 or more disorders. Wichstrom et al. ${ }^{22}$ found that children with anxiety disorders had only moderately elevated odds of having comorbid disorders compared with children without anxiety disorders, with the rates of comorbid disorders ranging from $4 \%$ (for conduct disorders) to $12 \%$ (for depressive disorders).

Studies that establish prevalence rates and detail patterns of comorbidity for generalized anxiety disorder, separation anxiety disorder, and social phobia, 3 of the most common, earliest onset, psychiatric disorders, would provide the basic information necessary for the establishment of formal mental health services for young children. Effective psychotherapeutic and psychopharmacological treatments have been developed for older children ${ }^{28}$, and younger children too could potentially benefit if we were able to develop a greater understanding of the presentation, prevalence, and specific patterns of comorbidity associated with these disorders. The Duke Preschool Anxiety Study aimed to 1) establish prevalence rates for generalized anxiety disorder, separation anxiety disorder, and social 
phobia according to the $D S M-I V$ criteria; 2) detail patterns of comorbidity among generalized anxiety disorder, separation anxiety disorder, and social phobia; and 3) examine the patterns of comorbidity among generalized anxiety disorder, separation anxiety disorder, and social phobia and other anxious or non-anxious disorders in preschool aged children in pediatric primary care.

\section{Method}

\section{Study Design}

The Duke Preschool Anxiety Study is a screen-stratified, cross-sectional study with three phases: 1) a primary care questionnaire screening phase, 2) an in-home parent interview phase, and 3) a lab-based case-control phase. The aim of this sampling strategy was to identify 250 children with and 250 children without anxiety disorders to participate in phase 3 , a nested case-control study (total $\mathrm{N}=500$ ). The determining factor for this sample size was based on power calculations to obtain enough children with clinically significant anxiety disorders to: a) produce reasonably narrow confidence intervals around the prevalence estimate of generalized anxiety disorder, separation anxiety disorder, and social phobia; and b) examine patterns of comorbidity of these three disorders. Phases one and two are illustrated in a figure (see Figure S1, available online) and described in detail below. Data presented in this paper focuses on the phase two sample.

Phase 1: Screening-Screening took place over 45 months (January 2007-October 2010). We screened children aged 2 through 5 years attending Duke Pediatric Primary Care Clinics. Primary care pediatric clinic samples have a number of important advantages: 1) rates of psychiatric disorder in randomly selected general pediatric primary care samples have been found to be similar to general population prevalence rates ${ }^{2930}$;2) most preschool children see a pediatrician at least annually; and 3) pediatricians see a large number of children per day, so collecting an adequate sample in a reasonable time is feasible.

Preschoolers scheduled for both well-child and sick-child visits on the specified recruitment day were identified using a tracking and scheduling system. When the child and their caregiver were in the examination room, the nurse asked the caregiver whether they were willing to speak with the screener regarding participation in a research study. If the caregiver agreed, the screener would obtain written consent from the caregiver and complete the screen.

Inclusion criteria were 1) the child was between 24 and 71 months old, and 2) the child attended the pediatric clinic during a screening period.

Exclusion criteria were 1) the child was not accompanied by a parent/legal guardian who could provide consent, 2) the parent/legal guardian did not have adequate fluency in English to complete the screen, 3 ) the index child was known to have mental retardation (IQ < 70), autism, or other pervasive developmental disorders, 4) the child's sibling was participating in the study already, or 5) the provider decided that the child was too medically ill at the visit for the parent to be approached about the study. There is considerable evidence that children and adolescents with autism spectrum disorders are at increased risk for anxiety disorders ${ }^{31}$. We also acknowledge that mental retardation is woefully understudied. However, less than $1 \%(\mathrm{n}=21)$ of our screened sample was known to have an autism spectrum disorder and/or mental retardation, and these extremely low prevalence rates would have made inclusion of these subgroups in our analyses problematic.

4,520 children ages $2-5$ years attended the Duke pediatric clinics on the screening days; 519 $(11.5 \%)$ were excluded from screening (for meeting any of the 5 exclusion criteria outlined 
above); $522(13 \%)$ parents refused to participate in screening, and we missed making contact with 46 parents $(1.1 \%)$. Thus, of the 4,001 eligible children, we screened 3,433 $(85.8 \%)$. There were no significant differences by age or sex between screen completers and noncompleters. Of the 3,433 children screened, 944 (27.5\%) screened high, and 2,490 $(72.5 \%)$ did not screen high. All of the children who screened high and a random sample of $189(7.5 \%)$ who did not screen high were selected to participate in phase 2: the in-home assessment phase.

Phase 2: In-home Assessment-In-home assessments took place over 47 months (January 2007-December 2010). The mean time lapse between screen completion and completion of the in-home assessment was 52.6 days (SD 115.8). Of the 1132 children selected to participate, 1,113 were eligible. Nineteen $(1.7 \%)$ were excluded (for meeting any of the 5 exclusion criteria mentioned above), and 196 (17.6\%) parents/legal guardians refused to participate. The Preschool Aged Psychiatric Assessment was completed by 917 (82.4\%) eligible parents. The interviewers were blind to the child's screen status. There were no significant differences by age or sex between those selected and those who completed the in-home interview. However, of those who refused the in-home interview, $80.6 \%$ had screened high. 391 children (30\%), whose parents completed the in-home assessment, were enrolled in Medicaid, a similar rate of coverage for children under the age of 18 in both North Carolina and the United States ${ }^{32}$

\section{Procedures}

The study design and methods were approved by Duke University School of Medicine Institutional Review Board (IRB). Prior to the initiation of each study phase, the parent or legal guardian signed informed consent forms approved by the Duke IRB. Parents were not compensated for completing the screening phase of the study. The primary parent/caregiver was given $\$ 75$ for completion of the in-home assessment. Parental/caregiver reimbursement was intended to pay for travel, parking, and childcare for siblings, and to reimburse participants for their time and effort.

\section{Measures}

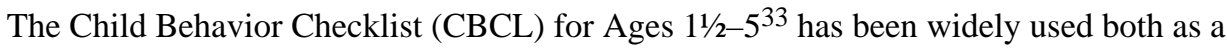
reliable measure of psychopathology in its own right and as a screening instrument for sample selection for more intensive assessments. The narrow-band anxious/depressed scale consisting of 10 items was used as the screening instrument in phase 1. A cutpoint based on data from an earlier study ${ }^{7}$ was used as a benchmark to identify a group consisting of approximately $25 \%$ of the primary care clinic sample who were at relatively high risk of having an anxiety disorder. The cutpoint was adjusted during the study to ensure that the correct proportion of participants (25\%) were being identified (cutpoint of 4 was used for $0.3 \%$ of the cohort, 5 for $62.0 \%$, and 7 for $37.7 \%$ ).

The Preschool Age Psychiatric Assessment (PAPA), a parent-report instrument for the assessment of psychopathology in 2- to 5-year-olds, is based on the parent version of the Child and Adolescent Psychiatric Assessment ${ }^{34}$. The PAPA uses a highly structured protocol, with requires questions and probes, however, the onus throughout is on the interviewer to ensure that interviewees 1) understand the question being asked; 2) provide clear information on behavior or feelings relevant to the symptom; and 3) report the symptom at a pre-specified level of severity as defined in an extensive glossary. Symptom frequency, duration and dates of onset are collected, to determine whether they meet symptom and duration criteria for DSM diagnoses. A 3-month "primary period" is used, because shorter recall periods are associated with more accurate recall ${ }^{35}$. The PAPA includes assessment of most $D S M-I V$ diagnostic criteria insofar as they are relevant to 
younger children. $D S M-I V$ diagnoses include: attention-deficit/hyperactivity disorder, oppositional defiant disorder, conduct disorder, depression (major depression, dysthymia and depression-not otherwise specified), anxiety disorders (separation anxiety disorder, generalized anxiety disorder, social phobia, specific phobia, posttraumatic stress disorder, and selective mutism), and elimination disorder (enuresis and encopresis). Impairment was based upon the World Health Organization's International Classification of Functioning, Disability and Health ${ }^{36}$. To avoid tapping into normative fears, impairment from anxiety was required for all anxiety diagnoses. Diagnostic reliability of the PAPA is on a par with those achieved by older child, adolescent, and adult psychiatric interviews ${ }^{7}$.

Sociodemographic variables (Table 1) include most of those examined in previous epidemiological studies of child-adolescent mental health ${ }^{37}$. Ethnic origin/race included: American Indian or Alaska Native, Asian, Hispanic, Native Hawaiian or Other Pacific Islander, Black or African American, White, and Other. Caregivers could mark off all categories applicable to the child. For the analyses: gender (male/female) and family income (above/at or below the federal poverty threshold ${ }^{32}$ ) had 2 levels; number of biological parents living with the child $(0,1,2)$ and ethnic origin/race (Hispanic, Non-Hispanic black, Non-Hispanic white) had 3 levels; and age $(2,3,4$, or 5), primary caregiver education (< high school, high school graduate, some college, college graduate), and number of siblings $(\geq 3,2,1,0)$ had 4 levels.

\section{Analytic Strategy}

To establish prevalence rates from a multistage sampling design subjects were assigned a weight inversely proportional to their probability of selection. Associations were tested using weighted regression models in a generalized estimating equations framework implemented by SAS PROC GENMOD, which computes robust standard errors to account for effects of the sample stratification. Comparisons between unadjusted and adjusted odds ratios were used to examine patterns of comorbidity. Two outcomes were possible: 1) unadjusted associations could remain significant in multivariable models accounting for other comorbid disorders, or 2) unadjusted associations could attenuate to non-significance in multivariable models accounting for other comorbid disorders.

\section{Results}

The screen performed adequately with a sensitivity of $56 \%$ and a specificity of $80 \%$.

Sociodemographic distributions from the in-home assessment phase are presented in Table 1. Our sample demographics were similar to those of the area (Durham County) where the clinics were located, but are not representative of all children in the U.S. Table 2 displays the prevalence rates for generalized anxiety disorder, separation anxiety disorder, and social phobia in preschool aged children in pediatric primary care. Multivariable regression analyses examining the association between preschool anxiety disorders and sociodemographic variables are presented in Table 2. Preschoolers who lived with a greater number of siblings were more likely to meet criteria for generalized anxiety disorder, social phobia, and any anxiety disorder. Preschoolers who lived with both biological parents were less likely to meet criteria for generalized anxiety disorder. Female preschoolers were more likely to meet criteria for separation anxiety disorder compared to male preschoolers.

Figure 1 presents the weighted rates of comorbidity among generalized anxiety disorder, separation anxiety disorder, and social phobia in the form of Venn diagrams, with the unweighted number of individuals in each 'pure' or comorbid group. Seventy percent $(\mathrm{n}=187)$ only met criteria for one of the 3 anxiety disorders, $23 \%(\mathrm{n}=103)$ met criteria for 2 anxiety disorders, and 7\% ( $\mathrm{n}=37)$ met criteria for all 3 anxiety disorders. 
Figure 2 presents the weighted rates of comorbidity among generalized anxiety disorder, separation anxiety disorder, and social phobia, and other anxious and non-anxious disorders (depression, attention deficit/hyperactivity disorder and/or disruptive behavior disorders) in the form of pie charts, with the unweighted number of individuals in each group. Generalized anxiety disorder displayed the greatest degree of comorbidity. Forty nine percent of children with generalized anxiety disorder only had anxiety disorders, compared with 59\% of the children with separation anxiety disorder, and $68 \%$ of the children with social phobia. Fifty one percent of children with generalized anxiety disorder had a comorbid non-anxious disorder, compared with $41 \%$ of children with separation anxiety disorder, and $32 \%$ of children with social phobia.

Table 3 displays 1) the weighted prevalence of generalized anxiety disorder, separation anxiety disorder, and social phobia, a) when the disorder is comorbid with another anxious or non-anxious disorder or b) when the disorder is not comorbid with another anxious or non-anxious disorder, 2) the unadjusted, and 3) the adjusted associations among generalized anxiety disorder, separation anxiety disorder, and social phobia, and other anxious or nonanxious disorders. The adjusted model provides pairwise associations after accounting for other comorbid conditions. Controlling for other comorbid conditions, generalized anxiety disorder displayed the greatest degree of comorbidity, as significant relationships were maintained with separation anxiety disorder (odds ratio $[\mathrm{OR}]=4.1,95 \% \mathrm{CI}, 2.0-8.5$ ), social phobia $(\mathrm{OR}=6.4,95 \% \mathrm{CI}, 3.1-13.4)$, disruptive behavior disorders $(\mathrm{OR}=5.1,95 \% \mathrm{CI}$, 1.6-15.8), and depression (OR $=3.7,95 \% \mathrm{CI}, 1.1-12.4)$. This means, for example, that controlling for other comorbid disorders, separation anxiety disorder was 4 times as likely in children with generalized anxiety disorder than in children without generalized anxiety disorder. Generalized anxiety disorder (OR 6.1, 95\% CI, 3.0-12.7), and attention deficit/ hyperactivity disorder (OR 3.1, 95\% CI, 1.1-8.7) remained significantly associated with social phobia after controlling for other comorbid disorders. Separation anxiety disorder displayed the least degree of comorbidity; after controlling for other comorbid conditions, the only significant relationship was with generalized anxiety disorder $(\mathrm{OR}=3.9,95 \% \mathrm{CI}$, 1.8-8.4). For the most part, associations between anxiety disorders and attention deficit/ hyperactivity disorder, disruptive behavior disorders, and interestingly depression were attenuated, or became nonsignificant in the adjusted models.

\section{Discussion}

Generalized anxiety disorder, separation anxiety disorder, and social phobia are common in preschool aged children attending pediatric primary care for nonpsychiatric reasons. Our prevalence rates are higher than those previously reported ${ }^{7,20-22}$. As 3 of the 4 comparable studies $^{7,21,22}$ used the PAPA, differences in sampling design, variability in response rates, and geographic location may explain the variation in prevalence rates.

Associations were found between generalized anxiety disorder and the number of biological parents in the household, such that living with both biological parents appeared to be protective. A higher prevalence of disorders among children exposed to single parenthood has been reported ${ }^{38}, 39$. Living with a greater number of siblings was associated an increased risk for generalized anxiety disorder, and social phobia. Kessler et al. ${ }^{37}$ reported a lower prevalence of disorders among adolescents with 1 versus 2 or more siblings. Female preschoolers were more likely to meet criteria for separation anxiety disorder. Studies have indicated a greater prevalence of separation anxiety disorder for girls than boys in both community ${ }^{40-4344}$ and clinical samples ${ }^{45}$. These findings highlight the importance of exploring more deeply other risk and protective factors associated with preschool anxiety disorders. 
Close to three quarters of preschoolers who met criteria for an anxiety disorder only had a single anxiety disorder. Of the 3 anxiety disorders, generalized anxiety disorder displayed the greatest degree of comorbidity. Findings from population-based twin studies suggest that generalized anxiety disorder shares genetic liability with depression ${ }^{46,47}$. A study by Sterba et al. ${ }^{10}$ suggested that the ways in which preschool psychopathology differentiation departs from $D S M-I V$ nosology are strikingly similar to those found in older children and adolescents: a lack of separation between generalized anxiety disorder and depression. However, the weakness of association, between generalized anxiety disorder and depression, in preschool aged children stands in contrast to substantial associations in older

individuals ${ }^{48-50}$. A developmental variation in the phenotype of generalized anxiety disorder has previously been suggested ${ }^{9}$. This may in part be explained by a differential course of anxiety in individuals from childhood to adulthood as a result of age-related changes in the genetic and environmental factors ${ }^{51}$, as well as variability in ages of onset ${ }^{52,53}$.

Limitations include the following: 1) this data is taken from phase 2 of the Duke Preschool Anxiety Study and is based solely on parent report. Phase 3 of this study, a lab-based casecontrol phase where 500 children completed observational assessments and cognitive and psychological testing, will help us gain a deeper understanding of the behavioral phenotypes of early onset anxiety, and their relationship to parent report of psychiatric symptomatology; 2) participants were recruited from pediatric primary care, and not from the community. The focus of this study was on psychiatric disorders and comorbidity among these disorders. We believe that very few, if any preschoolers attended primary care clinics because of mental health concerns and it is therefore unlikely that, for example, differences between generalized anxiety disorder/social phobia comorbidity would be affected by the fact that this is a clinic-based rather than a community-based sample; and 3) prevalence and comorbidity estimates were computed on the basis of a screen-stratified sample, with a screen that was $56 \%$ sensitive, with relatively few children who screened negative receiving a PAPA assessment. This could affect the reliability of the results. However, confidence intervals, an interval estimate of a population parameter, are provided for the reader to indicate the reliability of the estimates. The size of the confidence intervals reported in this study, are similar to other comparable studies ${ }^{7,20-22}$.

Comorbidity may play an important role in understanding the etiology, course, and treatment of children's mental health problems. An understanding of different comorbidity patterns may be an opportunity to move beyond DSM to characterize phenotypes that link genes with brain and behavior ${ }^{54}$. While very little attention has been paid to age effects on comorbidity, the malleability of the immature fear circuit in infants and young children suggests that it may be easier to shape amygdala-ventrolateral prefrontal cortex function and its effects on attention-bias in relatively young compared with older children ${ }^{55}$. The attenuated associations among disorders in preschool aged children demonstrated in this study could translate into clinical opportunities for early intervention and targeted treatment of young children. These interventions could potentially modify the developmental trajectory of anxiety disorders, lower rates of mental health disorders in older children, adolescents, and adults, and improve quality of life throughout the lifespan.

\section{Supplementary Material}

Refer to Web version on PubMed Central for supplementary material.

\section{Acknowledgments}

This research was supported by a grant from the National Institutes of Mental Health (NIMH; RO1-MH-075766). The content is solely the responsibility of the authors and does not necessarily represent the official views of NIMH or the National Institutes of Health (NIH). 
The authors are extremely grateful to the children and caregivers who took part in this study.

\section{References}

1. Gadow KD, Sprafkin J, Nolan EE. DSM-IVSymptoms in community and clinic preschool children. J Am Acad Child Adolesc Psychiatry. Dec; 2001 40(12):1383-1392. [PubMed: 11765283]

2. Cartwright-Hatton S, McNicol K, Doubleday E. Anxiety in a neglected population: prevalence of anxiety disorders in pre-adolescent children. Clin Psychol Rev. Nov; 2006 26(7):817-833. [PubMed: 16517038]

3. Egger HL. Psychiatric assessment of young children. Child Adolesc Psychiatr Clin N Am. Jul; 2009 18(3):559-580. [PubMed: 19486838]

4. Egger, HL.; Angold, A. Classification of Psychopathology in Early Childhood. In: Zeanah, CH., editor. Handbook of Infant Mental Health. 3. New York: Guilford; 2009. p. 285-300.

5. Zito JM, Safer DJ, Valluri S, Gardner JF, Korelitz JJ, Mattison DR. Psychotherapeutic medication prevalence in Medicaid-insured preschoolers. J Child Adolesc Psychopharmacol. Apr; 2007 17(2): 195-203. [PubMed: 17489714]

6. Olfson M, Crystal S, Huang C, Gerhard T. Trends in antipsychotic drug use by very young, privately insured children. J Am Acad Child Adolesc Psychiatry. Jan; 2010 49(1):13-23. [PubMed: 20215922]

7. Egger HL, Erkanli A, Keeler G, Potts E, Walter BK, Angold A. Test-Retest Reliability of the Preschool Age Psychiatric Assessment (PAPA). J Am Acad Child Adolesc Psychiatry. May; 2006 45(5):538-549. [PubMed: 16601400]

8. Clark C, Rodgers B, Caldwell T, Power C, Stansfeld S. Childhood and adulthood psychological ill health as predictors of midlife affective and anxiety disorders: the 1958 British Birth Cohort. Arch Gen Psychiatry. Jun; 2007 64(6):668-678. [PubMed: 17548748]

9. Mian ND, Godoy L, Briggs-Gowan MJ, Carter AS. Patterns of anxiety symptoms in toddlers and preschool-age children: evidence of early differentiation. J Anxiety Disord. Jan; 2012 26(1):102110. [PubMed: 22018968]

10. Sterba S, Egger HL, Angold A. Diagnostic specificity and nonspecificity in the dimensions of preschool psychopathology. Journal of Child Psychology and Psychiatry. 2007; 48(10):10051013. [PubMed: 17915001]

11. Pine DS, Cohen P, Gurley D, Brook J, Ma Y. The risk for early-adulthood anxiety and depressive disorders in adolescents with anxiety and depressive disorders. Arch Gen Psychiatry. Jan; 1998 55(1):56-64. [PubMed: 9435761]

12. Lieb R, Isensee B, Hofler M, Pfister H, Wittchen HU. Parental major depression and the risk of depression and other mental disorders in offspring: a prospective-longitudinal community study. Arch Gen Psychiatry. Apr; 2002 59(4):365-374. [PubMed: 11926937]

13. Costello EJ, Mustillo S, Erkanli A, Keeler G, Angold A. Prevalence and development of psychiatric disorders in childhood and adolescence. Arch Gen Psychiatry. Aug; 2003 60(8):837_ 844. [PubMed: 12912767]

14. Bittner A, Egger HL, Erkanli A, Jane Costello E, Foley DL, Angold A. What do childhood anxiety disorders predict? J Child Psychol Psychiatry. Dec; 2007 48(12):1174-1183. [PubMed: 18093022]

15. Copeland WE, Shanahan L, Costello EJ, Angold A. Childhood and adolescent psychiatric disorders as predictors of young adult disorders. Arch Gen Psychiatry. Jul; 2009 66(7):764-772. [PubMed: 19581568]

16. Shear K, Jin R, Ruscio AM, Walters EE, Kessler RC. Prevalence and correlates of estimated DSMIV child and adult separation anxiety disorder in the National Comorbidity Survey Replication. Am J Psychiatry. Jun; 2006 163(6):1074-1083. [PubMed: 16741209]

17. Kessler RC, McGonagle KA, Zhao S, et al. Lifetime and 12-month prevalence of DSM-III-R psychiatric disorders in the United States. Results from the National Comorbidity Survey. Arch Gen Psychiatry. Jan; 1994 51(1):8-19. [PubMed: 8279933]

18. Wittchen HU, Zhao S, Kessler RC, Eaton WW. DSM-III-R generalized anxiety disorder in the National Comorbidity Survey. Arch Gen Psychiatry. May; 1994 51(5):355-364. [PubMed: 8179459] 
19. Magee WJ, Eaton WW, Wittchen HU, McGonagle KA, Kessler RC. Agoraphobia, simple phobia, and social phobia in the National Comorbidity Survey. Arch Gen Psychiatry. Feb; 1996 53(2): 159-168. [PubMed: 8629891]

20. Lavigne JV, Lebailly SA, Hopkins J, Gouze KR, Binns HJ. The prevalence of ADHD, ODD, depression, and anxiety in a community sample of 4-year-olds. J Clin Child Adolesc Psychol. May; 2009 38(3):315-328. [PubMed: 19437293]

21. Bufferd SJ, Dougherty LR, Carlson GA, Klein DN. Parent-reported mental health in preschoolers: findings using a diagnostic interview. Compr Psychiatry. Jul-Aug;2011 52(4):359-369. [PubMed: 21683173]

22. Wichstrom L, Berg-Nielsen TS, Angold A, Egger HL, Solheim E, Sveen TH. Prevalence of psychiatric disorders in preschoolers. J Child Psychol Psychiatry. Jun; 2012 53(6):695-705. [PubMed: 22211517]

23. Costello, EJ.; Egger, HL.; Copeland, WE.; Erkanli, A.; Angold, A. The developmental epidemiology of anxiety disorders: phenomenology, prevalence, and comorbidity. In: Silverman, WK.; Field, AP., editors. Anxiety Disorders in Children and Adolescents. Cambridge University Press; 2011. p. 56-75.

24. Lavigne JV, Gibbons RD, Christoffel KK, et al. Prevalence rates and correlates of psychiatric disorders among preschool children. J Am Acad Child Adolesc Psychiatry. Feb; 1996 35(2):204214. [PubMed: 8720630]

25. Keenan K, Shaw DS, Walsh B, Delliquadri E, Giovannelli J. DSM-III-R disorders in preschool children from low-income families. J Am Acad Child Adolesc Psychiatry. May; 1997 36(5):620627. [PubMed: 9136496]

26. Hettema JM, Prescott CA, Myers JM, Neale MC, Kendler KS. The structure of genetic and environmental risk factors for anxiety disorders in men and women. Arch Gen Psychiatry. Feb; 2005 62(2):182-189. [PubMed: 15699295]

27. Scherrer JF, True WR, Xian H, et al. Evidence for genetic influences common and specific to symptoms of generalized anxiety and panic. J Affect Disord. Jan-Mar;2000 57(1-3):25-35. [PubMed: 10708813]

28. Annenberg Public Policy Center. Annenberg Adolescent Mental Health Project. 2003.

29. Costello EJ, Costello AJ, Edelbrock C, et al. Psychiatric disorders in pediatric primary care. Prevalence and risk factors. Arch Gen Psychiatry. Dec; 1988 45(12):1107-1116. [PubMed: 3264146]

30. Horwitz SM, Leaf PJ, Leventhal JM, Forsyth B, Speechley KN. Identification and management of psychosocial and developmental problems in community-based, primary care pediatric practices. Pediatrics. Mar; 1992 89(3):480-485. [PubMed: 1371342]

31. van Steensel FJ, Bogels SM, Perrin S. Anxiety disorders in children and adolescents with autistic spectrum disorders: a meta-analysis. Clin Child Fam Psychol Rev. Sep; 2011 14(3):302-317. [PubMed: 21735077]

32. U.S. Census Bureau. [Accessed July 1, 2013] Current Population Survey. http://www.census.gov/ hhes/www/cpstables/032012/health/toc.htm

33. Achenbach TM, Ruffle TM. The Child Behavior Checklist and related forms for assessing behavioral/emotional problems and competencies. Pediatr Rev. Aug; 2000 21(8):265-271. [PubMed: 10922023]

34. Angold A, Prendergast M, Cox A, Harrington R, Simonoff E, Rutter M. The Child and Adolescent Psychiatric Assessment (CAPA). Psychol Med. Jul; 1995 25(4):739-753. [PubMed: 7480451]

35. Angold A, Erkanli A, Costello EJ, Rutter M. Precision, reliability and accuracy in the dating of symptom onsets in child and adolescent psychopathology. J Child Psychol Psychiatry. Sep; 1996 37(6):657-664. [PubMed: 8894946]

36. World Health Organization. ICF: International classification of functioning, disability and health. Geneva: World Health Organization; 2001.

37. Kessler RC, Avenevoli S, Costello EJ, et al. Prevalence, persistence, and sociodemographic correlates of DSM-IV disorders in the National Comorbidity Survey Replication Adolescent Supplement. Arch Gen Psychiatry. Apr; 2012 69(4):372-380. [PubMed: 22147808] 
38. Fergusson DM, Boden JM, Horwood LJ. Exposure to single parenthood in childhood and later mental health, educational, economic, and criminal behavior outcomes. Arch Gen Psychiatry. Sep; 2007 64(9):1089-1095. [PubMed: 17768274]

39. Robinson M, Oddy WH, Li J, et al. Pre- and postnatal influences on preschool mental health: a large-scale cohort study. J Child Psychol Psychiatry. Oct; 2008 49(10):1118-1128. MANUSCRIPT. [PubMed: 19017026]

40. Gleason MM, Egger HL, Emslie GJ, et al. Psychopharmacological treatment for very young children: contexts and guidelines. J Am Acad Child Adolesc Psychiatry. Dec; 2007 46(12):15321572. [PubMed: 18030077]

41. Foley D, Rutter M, Pickles A, et al. Informant disagreement for separation anxiety disorder. J Am Acad Child Adolesc Psychiatry. Apr; 2004 43(4):452-460. [PubMed: 15187805]

42. Hale WW 3rd, Raaijmakers Q, Muris P, Meeus W. Psychometric properties of the Screen for Child Anxiety Related Emotional Disorders (SCARED) in the general adolescent population. J Am Acad Child Adolesc Psychiatry. Mar; 2005 44(3):283-290. [PubMed: 15725973]

43. Hewitt JK, Silberg JL, Rutter M, et al. Genetics and developmental psychopathology: 1. Phenotypic assessment in the Virginia Twin Study of Adolescent Behavioral Development. J Child Psychol Psychiatry. Nov; 1997 38(8):943-963. [PubMed: 9413794]

44. Ogliari A, Citterio A, Zanoni A, et al. Genetic and environmental influences on anxiety dimensions in Italian twins evaluated with the SCARED questionnaire. J Anxiety Disord. 2006; 20(6):760777. [PubMed: 16326068]

45. Last CG, Hansen C, Franco N. Anxious children in adulthood: a prospective study of adjustment. J Am Acad Child Adolesc Psychiatry. May; 1997 36(5):645-652. [PubMed: 9136499]

46. Kendler KS. Major depression and generalised anxiety disorder. Same genes, (partly)different environments--revisited. Br J Psychiatry Suppl. Jun.1996 30:68-75. [PubMed: 8864151]

47. Kendler KS, Neale MC, Kessler RC, Heath AC, Eaves LJ. Major depression and generalized anxiety disorder. Same genes, (partly) different environments? Arch Gen Psychiatry. Sep; 1992 49(9):716-722. [PubMed: 1514877]

48. Moffitt TE, Caspi A, Harrington H, et al. Generalized anxiety disorder and depression: childhood risk factors in a birth cohort followed to age 32. Psychol Med. Mar; 2007 37(3):441-452. ACCEPTED MANUSCRIPT. [PubMed: 17201999]

49. Moffitt TE, Harrington H, Caspi A, et al. Depression and generalized anxiety disorder: cumulative and sequential comorbidity in a birth cohort followed prospectively to age 32 years. Arch Gen Psychiatry. Jun; 2007 64(6):651-660. [PubMed: 17548747]

50. Watson D. Rethinking the mood and anxiety disorders: a quantitative hierarchical model for DSMV. J Abnorm Psychol. Nov; 2005 114(4):522-536. [PubMed: 16351375]

51. Lamb DJ, Middeldorp CM, van Beijsterveldt CE, et al. Heritability of anxious-depressive and withdrawn behavior: age-related changes during adolescence. J Am Acad Child Adolesc Psychiatry. Mar; 2010 49(3):248-255. [PubMed: 20410714]

52. Costello, EJ.; Egger, HL.; Copeland, W.; Erkanli, A.; Angold, A. The developmental epidemiology of anxiety disorders: phenomenology, prevalence, and comorbidity. In: Silverman, WK.; Field, AP., editors. Anxiety Disorders in Children and Adolescents. 2. Cambridge University Press; 2011.

53. Beesdo K, Knappe S, Pine DS. Anxiety and anxiety disorders in children and adolescents: developmental issues and implications for DSM-V. Psychiatr Clin North Am. Sep; 2009 32(3): 483-524. [PubMed: 19716988]

54. Insel TR, Fenton WS. Psychiatric epidemiology: it's not just about counting anymore. Arch Gen Psychiatry. Jun; 2005 62(6):590-592. [PubMed: 15939836]

55. Hakamata Y, Lissek S, Bar-Haim Y, et al. Attention bias modification treatment: a meta-analysis toward the establishment of novel treatment for anxiety. Biol Psychiatry. Dec 1; 2010 68(11):982990. [PubMed: 20887977] 


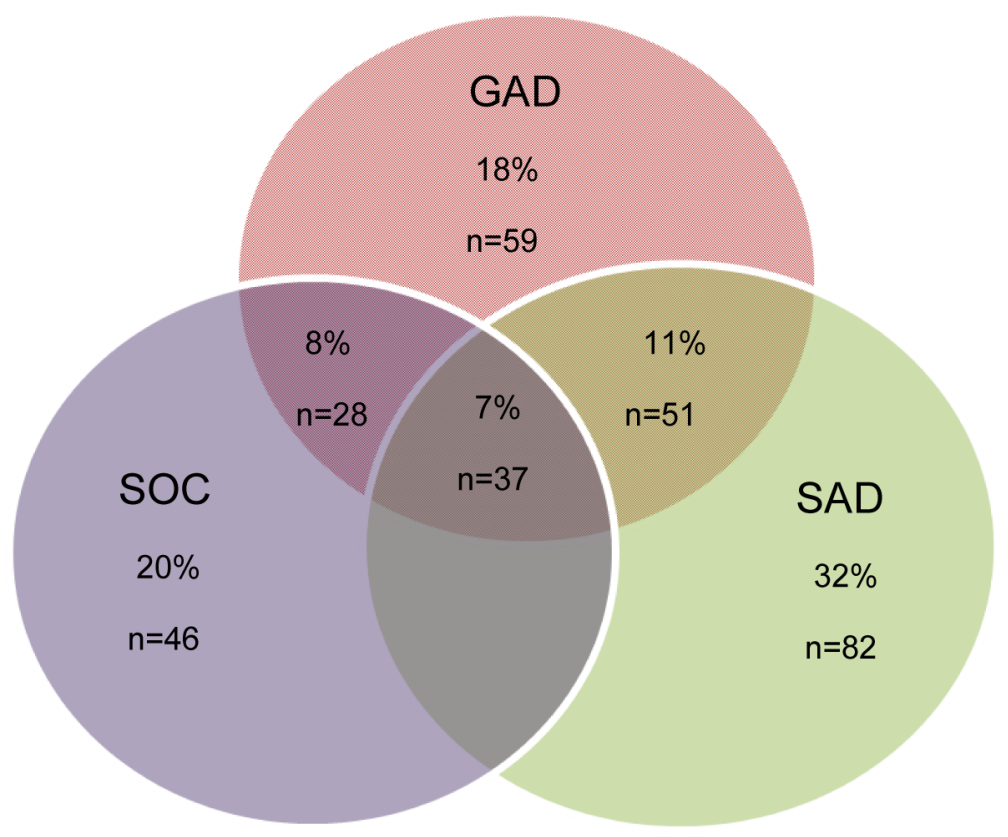

Figure 1.

Comorbidity among generalized anxiety disorder (GAD), separation anxiety disorder (SAD), and social phobia (SOC). Note: Percentages add up to $100, \mathrm{n}=327$. Figure 2 shows comorbidity across all disorders. $\mathrm{n}=$ unweighted number in group; $\%=$ weighted percentage. 
Comorbidity in

generalized anxiety disorder $n=175$

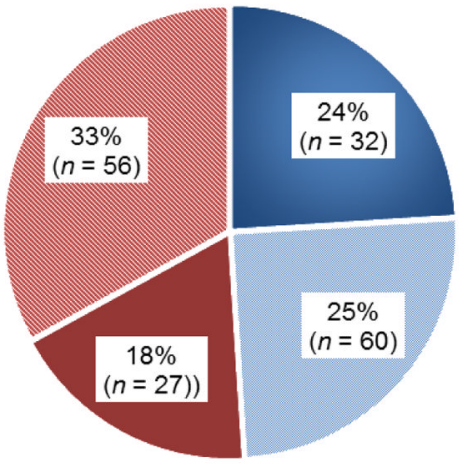

Comorbidity in social phobia $n=135$

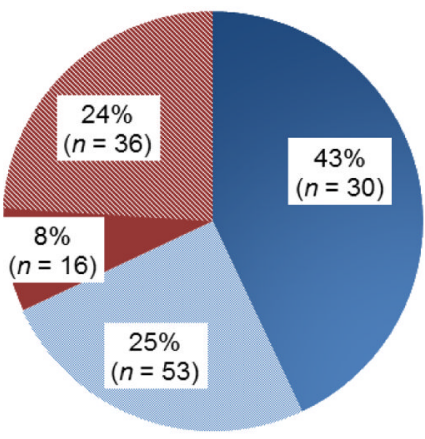

Comorbidity in

seperation anxiety disorder $n=194$

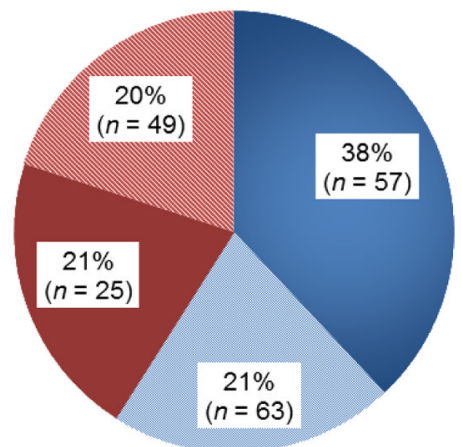

- Single anxiety disorder

- Two or more anxiety disorders with no non-anxious disorder(s)

- Single anxiety disorder with one or more nonanxious disorder(s)

* Two or more anxiety disorders with one or more non-anxious disorder(s)

Figure 2.

Comorbidity across all disorders in preschoolers with anxiety disorders. Note: Percentages add up to 100. ADHD = attention-deficit/hyperactivity disorder; DBD = disruptive behavior disorders (oppositional defiant disorder or conduct disorder); $\mathrm{n}=$ unweighted number in group; non-anxious disorders = depression (major depressive disorder, depression-not otherwise specified [NOS], or dysthymia); $\%=$ weighted percentage. 
Table 1

Sociodemographic Distributions

\begin{tabular}{|c|c|c|c|}
\hline & \multicolumn{2}{|c|}{ DPAS } & \multirow{2}{*}{$\frac{\text { Durham County }{ }^{a}}{\text { Weighted } \%}$} \\
\hline & Unweighted n & Weighted \% & \\
\hline & Overall $\mathrm{N}=917$ & & $N=267,587$ \\
\hline Age, years & & & N/A \\
\hline 2 & 276 & 26.6 & \\
\hline 3 & 241 & 26.1 & \\
\hline 4 & 172 & 17.9 & \\
\hline 5 & 228 & 29.4 & \\
\hline \multicolumn{4}{|l|}{ Gender } \\
\hline Male & 466 & 48.2 & 47.7 \\
\hline Female & 451 & 51.8 & 52.3 \\
\hline \multicolumn{4}{|l|}{ Ethnic origin/Race } \\
\hline Hispanic & 104 & 12.8 & 13.5 \\
\hline Non-Hispanic black & 383 & 32.2 & 38.0 \\
\hline Non-Hispanic white & 347 & 46.9 & 46.4 \\
\hline American Indian or Alaska Native & 2 & 0.4 & 0.5 \\
\hline Asian & 24 & 2.3 & 4.6 \\
\hline Native Hawaiian or Other Pacific Islander & 1 & 0.04 & 0.1 \\
\hline Two or more races & 55 & 5.3 & 2.6 \\
\hline Other & 0 & 0 & 7.9 \\
\hline \multicolumn{4}{|l|}{ Family income $b$} \\
\hline Below federal poverty level & 169 & 11.9 & 17.1 \\
\hline \multicolumn{4}{|l|}{ Primary caregiver education } \\
\hline$<$ High school & 121 & 8.4 & 13.1 \\
\hline High school graduate & 150 & 14.3 & 18.7 \\
\hline Some college & 275 & 23.1 & 17.4 \\
\hline College graduate & 368 & 54.2 & 50.8 \\
\hline Biological parents living with child & & & N/A \\
\hline 0 & 50 & 3.6 & \\
\hline 1 & 326 & 25.2 & \\
\hline 2 & 541 & 71.2 & \\
\hline Siblings, number & & & N/A \\
\hline 23 & 79 & 7.2 & \\
\hline 2 & 162 & 19.1 & \\
\hline 1 & 395 & 45.3 & \\
\hline 0 & 281 & 28.4 & \\
\hline
\end{tabular}

Note: DPAS = Duke Preschool Anxiety Study.

${ }^{a}$ Information from the 2010 U.S. Census Report (www.factfinder2.census.gov). 
${ }^{b}$ Family income missing variables $=72$ 


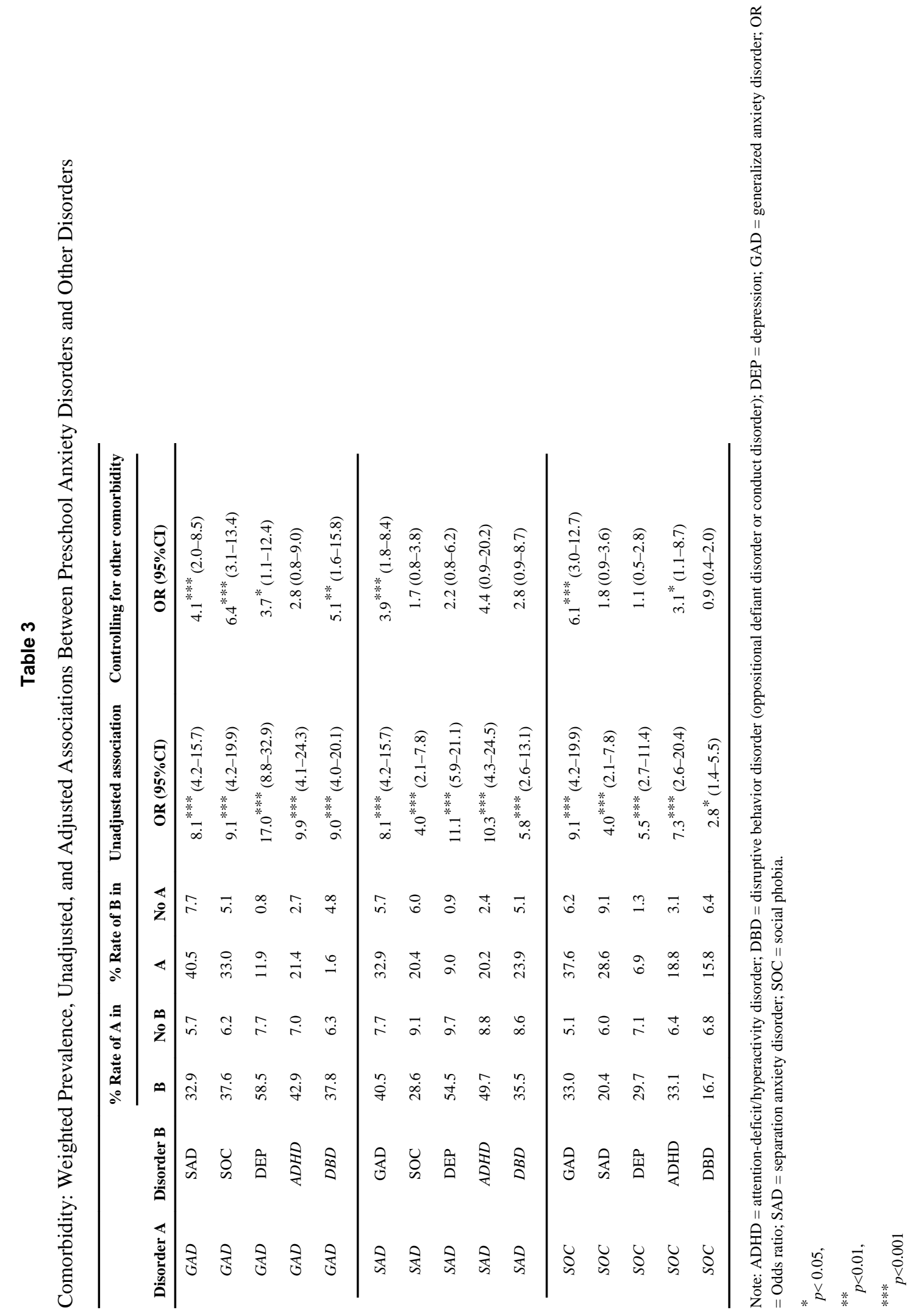

